Published in final edited form as:

N Engl J Med. 2004 June 10; 350(24): 2441-2451.

\title{
A Factorial Trial of Six Interventions for the Prevention of Postoperative Nausea and Vomiting
}

\author{
Christian C. Apfel, M.D., Kari Korttila, F.R.C.A., Ph.D., Mona Abdalla, Ph.D., Heinz Kerger, \\ M.D., Alparslan Turan, M.D., Ina Vedder, M.D., Carmen Zernak, M.D., Klaus Danner, M.D., \\ Ritva Jokela, M.D., Ph.D., Stuart J. Pocock, Ph.D., Stefan Trenkler, M.D., Markus Kredel, \\ M.D., Andreas Biedler, M.D., Daniel I Sessler, M.D., Norbert Roewer, M.D., and on behalf of \\ the IMPACT investigators, \\ Received from the Klinik und Poliklinik für Anaesthesiologie, Julius-Maximilians Universität,

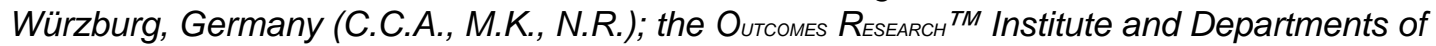 \\ Anesthesiology (C.C.A., D.I.S.) and Pharmacology (D.I.S), University of Louisville, Kentucky, USA; \\ the Medical Statistics Unit, London School of Hygiene and Tropical Medicine, London, United \\ Kingdom (M.A., S.P.); the Department of Anesthesiology and Intensive Care, Helsinki University \\ Central Hospital, Finland (K.K., R.J.); the Klinik für Anästhesiologie und Intensivmedizin, \\ Universitätsklinik Mannheim, Germany (H.K.); the Department of Anesthesiology and Reanimation, \\ Trakya University Hospital, Edirne, Turkey (A.T.); the Klinik für Anästhesiologie und operative \\ Intensivmedizin, v. Bodelschwingsche Anstalten Bethel, Bielefeld, Germany (I.V.); the Abteilung für \\ Anästhesiologie, operative Intensivmedizin und Blutprodukte, Kreiskrankenhaus Garmisch- \\ Patenkirchen, Germany (C.Z.); the Institut für Anästhesiologie und Notfallmedizin, Westpfalz- \\ Klinikum, Kaiserslautern, Germany (K.D.); the Department of Anesthesiology, Reiman University \\ Hospital, Presov, Slovakia (S.T.); the Klinik für Anästhesiologie und Intensivmedizin, \\ Universitätskliniken des Saarlandes, Homburg, Germany (A.B.); and
}

\section{Abstract}

Background-Untreated, one third of surgical patients suffer postoperative nausea and vomiting (PONV). The relative benefit of prophylactic interventions remains unknown, as does the efficacy of combining interventions. We therefore compared the efficacy of six antiemetic interventions and their combinations.

Methods-5199 patients at high risk for PONV participated in a randomized, controlled trial of factorial design powered to evaluate interactions between up to three antiemetic interventions. 4123

\footnotetext{
Address correspondence to Dr. Christian C. Apfel, Outcomes ResearCH ${ }^{\mathrm{TM}}$ Institute, 501 East Broadway, Suite 210, Louisville, KY 40202 , USA. E-mail:apfel@ ponv.org. Phone: (502) 298 8932. Fax: (502) 852 2610. On the world wide web: www.or.org..

the IMPACT investigators (listed in the appendix).

This study was supported by the Klinik für Anaesthesiologie, Grant 1518 TG 72, Julius-Maximilians Universität, Würzburg, Germany; Helsinki University Central Hospital, HUS-EVO Grant TYH 0324, University of Helsinki, Finland; AstraZeneca, Tinsdaler Weg 183, D-22876 Wedel, Germany; GlaxoSmithkline, Alsterufer 1, D-20354 Hamburg, Germany; the Gheens Foundation, Louisville, KY; the Joseph Drown Foundation, Los Angeles, CA; the Commonwealth of Kentucky Research Challenge Trust Fund, Louisville, KY; and the National Institutes of Health Grant GM 061655, Bethesda, MD.

Presented in part at the European Society of Anaesthesiologists, Glasgow, Scotland, June 2003; German Society of Anesthesiologists, Munich, Germany, April 2003; and American Society of Anesthesiologists, San Francisco, CA, October 2003.

Disclosure statement: None of the authors has a personal financial interest in the results of this study. Design, conduct, analysis, and interpretation were all independent from any sponsoring source. Dr Apfel has served as a paid speaker and received grant support from AstraZeneca (Germany) and GlaxoSmithkline (Germany) and served as a consultant for GlaxoSmithkline (Germany). Unrelated to the products discussed in this paper but related to antiemetics, Dr Apfel has served as a consultant for Merck (Whitehouse, NJ) and Helsinn Healthcare (Switzerland). Dr Korttila has served as a consultant for Pharmacia/Pfizer (Germany) and Helsinn Healthcare (Switerzerland) and paid speaker for Pharmacia/Pfizer. Dr Apfel and Dr Sessler received a writing grant from Pfizer (New London, CT). Unrelated to the field of antiemetic interventions, Dr Sessler received grants from Merck (Whitehouse, NJ), Progenics (Tarrytown, NJ), Cardinal Health McGraw Park, IL), Pfizer (New London, CT), Ocean Optics (Dunedin, FL), Scott Laboratories (Lubbock, TX).
} 
patients were randomly assigned to one of 64 possible combinations of six prophylactic interventions: 1) $4 \mathrm{mg}$ vs. no ondansetron; 2) $4 \mathrm{mg}$ vs. no dexamethasone; 3) $1.25 \mathrm{mg}$ vs. no droperidol; 4) propofol vs. a volatile anesthetic; 5) nitrogen vs. nitrous oxide; and 6) remifentanil vs. fentanyl. An additional 796 patients were randomized to 4 of all 6 interventions and an additional 280 patients were randomized to $80 \%$ oxygen in nitrogen as a third alternative to intervention 5 . The blindly evaluated primary outcome was PONV within 24 hours.

Results-5123 (99\%) patients randomized to four interventions and 4086 of the 4123 patients (99\%) randomized to all six interventions completed the study. Based on 4086 patients, ondansetron, dexamethasone, and droperidol each reduced PONV risk by about $26 \%$. Propofol reduced risk by $19 \%$ and nitrogen by $12 \%$; risk reduction with total intravenous anesthesia was thus similar to that resulting from antiemetics. All interventions acted independently, so that relative risk reduction for combined interventions could be estimated by the product of individual relative risk reductions. Similar results were obtained when all 5123 patients were analyzed.

Conclusions-Since each antiemetic drug and the total intravenous anesthesia similarly reduce relative risk, it seems sensible to use the least expensive or safest intervention first. Absolute risk is reduced less by additional interventions since the apparent baseline risk is already reduced. It is the patient's initial risk therefore, which determines whether and how many interventions will produce a clinically relevant absolute risk reduction in PONV.

\section{Keywords}

randomized controlled trial; factorial design; postoperative nausea and vomiting; antiemetics; propofol; PONV

\section{Introduction}

Anesthesia is given worldwide to more than 75 million surgical patients annually. Untreated, one third will suffer postoperative nausea, vomiting, or both (PONV). ${ }^{1-3}$ Patients often rate PONV as worse than postoperative pain. ${ }^{4,5} \mathrm{It}$ is not surprising, therefore, that preventing PONV improves satisfaction in patients likely to experience PONV. ${ }^{6}$ Vomiting increases the risk of aspiration and has been associated with suture dehiscence, esophageal rupture, subcutaneous emphysema, and bilateral pneumothoraces. 7,8 PONV frequently delays discharge from postanesthesia care units and is the leading cause of unexpected hospital admission after planned ambulatory surgery. ${ }^{9}$ The annual cost of PONV in the United States is thought to be several hundred million dollars. 10,11

More than 1,000 randomized controlled trials have evaluated pharmacologic methods of preventing and treating PONV. Most compared a single intervention with placebo. Serotonin (5HT 3 )-antagonists (e.g., ondansetron), dexamethasone (a steroid), and droperidol (a neuroleptic drug) are among the best-studied antiemetics. Alternatively, avoiding emetogenic influences during anesthesia can reduce the baseline risk of PONV. This strategy includes giving propofol instead of volatile anesthetics, substituting nitrogen for nitrous oxide, and using the ultra-short acting opioid remifentanil instead of fentanyl. ${ }^{12}, 13$

Limited treatment efficacy with single antiemetics ${ }^{14}$ has prompted studies that evaluated combinations of several antiemetic strategies. ${ }^{15}$ However, no previous study of PONV has had an appropriate design and sufficient power to simultaneously evaluate all major pharmacologic interventions or determine the extent to which combining multiple interventions improves outcome. A recent consensus conference was thus unable to support a definitive statement on the benefits of combining antiemetic strategies. ${ }^{16}$ We therefore conducted a large clinical trial of factorial design with sufficient power to compare the efficacy 
of six well-established antiemetic strategies, while simultaneously determining the extent to which efficacy could be improved by combining two or three interventions.

\section{Methods}

The design, center recruitment, data management and acquisition, statistical analyses, writing, editing, and interpretation were performed independently from the sponsors. Details of the individual author contributions are listed in the appendix.

With approval of the institutional review boards and written informed consent, 5199 adults, scheduled for elective surgery with general anesthesia expected to last at least one hour, were enrolled in 28 centers. All patients had a PONV risk exceeding $40 \%$ according to a simplified risk score; ${ }^{17}$ i.e., each had at least two of the following risk factors: female gender, non-smoker, previous history of PONV and/or motion sickness, and anticipated use of postoperative opioids. 18,19 We excluded patients in whom any of the study drugs were contraindicated, who had taken emetogenic or antiemetic drugs within 24 hours before surgery, who were expected to require postoperative mechanical ventilation, or who were pregnant or lactating.

\section{Protocol}

Anti-emetic efficacy of six individual treatments and their combinations were simultaneously evaluated with a $2^{6}$-factorial design. ${ }^{20}$ Three of the prophylactic interventions were anti-emetic drugs: ondansetron, dexamethasone, and droperidol. The other three interventions consisted of using propofol instead of volatile anesthetics, omitting nitrous oxide, and substituting the ultra-short-acting opioid remifentanil for fentanyl.

Our design was to randomize every patient to each of the following six treatments:

1. Ondansetron (4 mg IV) vs. no ondansetron;

2. Dexamethasone (4 mg IV) vs. no dexamethasone;

3. Droperidol (1.25 mg IV) vs. no droperidol;

4. Propofol vs. volatile anesthesia (i.e., isoflurane, desflurane, or sevoflurane) in a 2:1 ratio;

5. Nitrogen vs. nitrous oxide;

6. Remifentanil vs. fentanyl.

These six treatments lead to $64\left(2^{6}\right)$ different treatment combinations. However, because propofol is associated with a reduced PONV risk, ${ }^{21}$ to assure sufficient power to quantify the effect of antiemetics in the propofol subgroup, we assigned twice as many patients to propofol compared to volatile anesthetics (2:1 randomization ratio). Therefore, permutated blocks of 96 $\left(2^{3} \times 3 \times 2^{2}\right)$ patients were generated. Each center received 4 blocks with a unique computerized randomization, which was stored in sequentially numbered, sealed opaque envelopes. The three centers which used $80 \%$ oxygen in nitrogen (as a third alternative to factor 5) received 2 blocks of $144\left(2^{3} \times 3 \times 3 \times 2\right)$ patients. The envelopes were opened after consent was obtained, just before induction of general anesthesia. Anesthesiologists responsible for intraoperative management were not blinded to treatment, but were not involved in the postoperative assessment.

Supplemental oxygen may 22,23 or may not ${ }^{24,25}$ have an anti-emetic effect. Consequently, three centers randomized patients to $30 \%$ oxygen in nitrous oxide, $30 \%$ oxygen in nitrogen, or $80 \%$ oxygen in nitrogen in a ratio of $1: 1: 1$. This resulted in a minimum of $144(3 \times 48)$ patients per block. To provide sufficient power, each center agreed to study twice as many patients (288). 
Patients were premedicated with a benzodiazepine. Three minutes before induction of anesthesia, they received either a bolus of 100-200 $\mu \mathrm{g}$ fentanyl or an infusion of remifentanil $\left(0.25 \mu \mathrm{g} \cdot \mathrm{kg}^{-1} \cdot \mathrm{min}^{-1}\right)$. Anesthesia was induced with $2-3 \mathrm{mg} \cdot \mathrm{kg}^{-1}$ intravenous propofol (Disoprivan ${ }^{\circledR}$, Diprivan ${ }^{\circledR}$, AstraZeneca, Hamburg, Germany), and tracheal intubation was facilitated with rocuronium.

Normocapnic mechanical ventilation was instituted with the designated gas combination. Anesthesia was maintained with either propofol (starting at about $80 \mu \mathrm{g} \cdot \mathrm{kg}^{-1} \cdot \mathrm{h}^{-1}$ ) or a standardized concentration of a volatile anesthetic. If heart rate or blood pressure deviated more than $20 \%$ from the preoperative value, a 50 to $100-\mu \mathrm{g}$ intravenous bolus of fentanyl was given or the remifentanil infusion rate was increased slightly. Additionally, the concentration of volatile anesthetics and the propofol infusion rate could be adjusted as clinically appropriate. In designated patients, $4 \mathrm{mg}$ dexamethasone or $1.25 \mathrm{mg}$ droperidol was given intravenously within 20 minutes after starting anesthesia 10,26 or $4 \mathrm{mg}$ ondansetron was given intravenously during the last 20 minutes of surgery. 27

Postoperatively, patients received supplemental oxygen and pain was ameliorated by intraoperative administration of non-steroidal antiinflammatory medications; patients assigned to intraoperative remifentanil were given $50 \mu \mathrm{g} \cdot \mathrm{kg}^{-1}$ morphine or an equivalent opioid at the end of surgery. The need for postoperative opioids was left to the discretion of the anesthesiologist, and dose was adjusted according to clinical needs. Patients who requested antiemetic therapy or who suffered an emetic episode were given $4 \mathrm{mg}$ ondansetron; if symptoms persisted, $4 \mathrm{mg}$ dexamethasone and $1.25 \mathrm{mg}$ droperidol were added.

\section{Measurements}

Our primary outcome was the incidence of any nausea, emetic episodes (retching or vomiting), or both (i.e., PONV) during the first 24 postoperative hours. At the 2 nd and 24 th postoperative hours, trained investigators, fully blinded to intraoperative management, recorded the number and time of every emetic episode. Patients verbally rated their worst nausea episodes in each interval on an 11-point scale.

\section{Data Analysis}

Different sample-size estimations were performed and resulted in about 5000 patients to be randomized for up to three-factor interactions while the number of required patients for twofactor interactions or single factors was considerably smaller. ${ }^{20}$ An interaction is defined as present if the effect of two factors in combination is significantly different from the separate effects of each factor multiplied together on an odds ratio scale.

The numbers of patients suffering from PONV in each of the six randomized treatments were compared using chi-square tests for each main effect, along with estimated relative risk reductions.

Logistic regression analyses quantified the relative impact of the six interventions by odds ratio and identified potential two- or three-factor interactions by a stepwise forward-inclusion algorithm. This analysis was repeated to compensate for the covariates female gender, nonsmoking status, age, history of PONV or motion sickness, use of postoperative opioids, type of surgery and study center. Throughout, two-sided $\mathrm{P}<0.05$ was considered statistically significant.

\section{Results}

Patients were recruited from February 2, 2000 until July 30, 2002 in 28 centers; 5199 patients were factorially randomized to ondansetron, dexamethasone, droperidol, and propofol. 
Outcomes were incomplete in 38 patients leaving 5161. One center each did not randomize for carrier gas $(n=424)$, remifentanil $(n=191)$, or both $(n=181)$. Three centers randomized a total of 280 patients to $80 \%$ oxygen in nitrogen as a third alternative to $30 \%$ oxygen in nitrogen or in nitrous oxide. A total of 4123 patients were thus randomized to all six primary factors with incomplete outcomes in 37 patients (one patient with incomplete data was among those not randomized for carrier gas), leaving 4086 patients (Fig. 1).

Of the 5161 patients the $81.5 \%$ were female, $81.2 \%$ were non-smoker, $54.5 \%$ had a history of PONV or motion sickness, and $78.1 \%$ received postoperative opioids. Hernia repair occurred in $2.8 \%$ of the patients, cholecystectomy in $7.7 \%$, hysterectomy in $16.9 \%$, thyroid surgery in $5.9 \%$, breast surgery in $2.8 \%$, hip replacement in $3.5 \%$, knee arthroscopy in $2.2 \%$, upper extremity surgery in $2.5 \%$, head and neck (including ophthalmic) surgery in $9.0 \%$, other gynecological surgery in $28.2 \%$, other bone surgery in $6.6 \%$, and other types of general surgery in $11.7 \%$. The baseline characteristics were similar across patients randomized to each interventions; more detailed information can be found on the world-wide-web (Web Table 1).

Overall, 1731 of 5161 patients (34\%) experienced PONV. This reflects an average of all possible 64 combinations, ranging from 59\% (26/44) in patients given volatile anesthesia, nitrous oxide, fentanyl, and no antiemetics to $17 \%$ (17/102) in patients who received all six interventions. Nausea occurred in 1617 (31.3\%) and vomiting in 734 (14.2\%) patients. Of those patients experiencing symptoms, the median and mean for the maximum nausea level was 5 and 5.7 and for the number of emetic episodes 1 and 1.52, respectively. According to bivariate analyses, each antiemetic reduced the incidence of PONV by about 26\%; propofol reduced it by $19 \%$; and nitrogen by $12 \%$ (Table 1 ). Hypotension, use of intraoperative vasoconstrictors, and shivering were similar with each antiemetic. Propofol was associated with a lower use of intraoperative vasoconstrictors $(15 \%)$ than volatile anesthetics $(20 \%, P=0.001)$. The use of remifentanil rather than fentanyl did not significantly reduce the incidence of PONV, but was associated with an increased use of intraoperative vasoconstrictors $(21 \%$ vs. $13 \%, \mathrm{P}<0.001)$ and increased shivering $(6.7 \%$ vs. $3.3 \%, P<0.001)$.

Increasing the number of antiemetics reduced the incidence of PONV: 52\%, 37\%, 28\%, and $22 \%$ for zero, one, two, and three antiemetics, respectively (Fig. 2). This corresponds to a $26 \%$ reduction in the relative risk for each additional antiemetic used (95\%, CI 23\% to $30 \%)$. Furthermore, there were no significant differences among the antiemetics $\left(\chi^{2}\right.$ df $2=0.01, P=$ $1.00)$ or among any pair of antiemetics $\left(\chi_{\mathrm{df} 2}^{2}=0.42, P=0.81\right)$.

The effects of the anesthetic interventions and their combinations were explored in the 4086 patients randomized to all six interventions. The incidence of PONV was $41 \%$ for patients given a volatile anesthetic and nitrous oxide; $34 \%$ for a volatile anesthetic and nitrogen; $32 \%$ for propofol and nitrous oxide; and 29\% for propofol and nitrogen (Fig. 3). There was no significant interaction between propofol and nitrogen (likelihood ratio test $\chi_{\mathrm{df}=2}^{2}=0.94, \mathrm{P}=$ 0.33 ). Although the type of volatile anesthetic (isoflurane, sevoflurane, desflurane) was not a randomized factor, it had no significant impact on PONV in a multivariate model $(P=0.30)$.

The incidence of PONV was $31 \%$ in the patients receiving $80 \%$ oxygen in nitrogen and $24 \%$ in the patients receiving $30 \%$ oxygen in nitrogen $(P=0.07)$.

Multivariate logistic analyses of data from the whole dataset (5161 patients) and those receiving all six treatments (4086 patients) are shown in Table 2. This analysis found no significant interactions among the treatments. When the interactions between treatments and potentially confounding factors (e.g., type of surgery) were analyzed, there was only one significant interaction: droperidol and gender $(P=0.003)$. Droperidol reduced PONV risk from $43 \%$ $(910 / 2106)$ to $32 \%(662 / 2101)$ in women (odds ratio $0.61,95 \%$ CI $0.53-0.69, P<0.001$ ) independent of menstrual cycle phase or menopause, whereas droperidol failed to significantly 
reduce the incidence in men: $17 \%$ (80/472) vs. $16 \%$ (79/482) (odds ratio $1.04,95 \%$ CI 0.74 $1.46, P=0.82)$.

The results based on 4086 patients remained essentially unchanged when all 5161 patients were considered, when potential confounders, or both were included in the statistical models (Table $3)$.

Based on the results that a total intravenous anesthesia or any antiemetic independently reduces the patients risk by about $26 \%$, the incidences for PONV at five different initial risks are given for up to four interventions in Table 3.

\section{Discussion}

The large enrollment and factorial design of our trial allowed simultaneous evaluation of the antiemetic efficacy of three antiemetic and three anesthetic interventions, and all combinations of two or three interventions.

All tested antiemetics appeared to be similarly effective. Ondansetron and other $5 \mathrm{HT}_{3}$ antagonists are considered relatively safe, but more expensive than droperidol and dexamethasone. However, low-dose droperidol can cause dysphoria 28,29 and the United States Food and Drug Administration recently added a "black box" warning to the drug's labeling as it may be associated with torsades des pointes - although there is little evidence that antiemetic doses trigger this condition. ${ }^{30}$ No studies identify complications associated with the antiemetic dose of dexamethasone, although even meta-analyses may have insufficient power to detect rare complications. ${ }^{31}$ The combination of low cost and apparent safety makes $4 \mathrm{mg}$ dexamethasone an attractive first-line prophylaxis for PONV.

Bivariate analysis indicated that substituting propofol for a volatile anesthetic reduced risk $19 \%$, whereas substituting nitrogen for nitrous oxide reduced risk $12 \%$. Combining these two anesthetic management strategies (i.e., total intravenous anesthesia) thus reduced the PONV risk about as much as any single antiemetic. In contrast, using remifentanil instead of fentanyl did not significantly reduce PONV.

The relative risk reduction for each intervention was apparently independent for a wide range of absolute risks. Thus, interventions that comparably reduce relative risk will produce the greatest absolute risk reduction in patients most likely to experience PONV. For example, a single intervention in a patient with an $80 \%$ risk for PONV will reduce the risk to about $60 \%$; this is an about $20 \%$ absolute risk reduction, which translates into a number-needed-to-treat of about 5. Conversely, the absolute risk reduction in a patient with a baseline risk of $10 \%$ is only about $2.5 \%$; this corresponds to a number-needed-to-treat of about 40 , which would probably not justify the expense and risk of prophylactic treatment. The efficacy of an intervention thus depends critically on the patient's baseline risk (Table 3).

Interestingly, there were no significant interactions among the antiemetics, among the anesthetic interventions, or among the anesthetic interventions and the antiemetics. The resulting relative risk for a combination of interventions can thus be directly calculated as the product of the individual relative risks. A consequence is that absolute risk reduction provided by a second or third intervention is less than for the initial intervention (irrespective which combination is chosen). A 70\% relative reduction in PONV risk is thus the best that can be expected, even when a total intravenous anesthesia is combined with three antiemetics (Fig. 3 , Table 3).

Because each tested antiemetic and total intravenous anesthesia comparably reduced relative risk, the logical sequence is to use the least expensive or safest intervention first. Further 
interventions with greater cost and greater chance of side effects will further reduce absolute risk less than the initial intervention. Combining prophylactic interventions therefore markedly increases cost and likelihood of side effects while providing progressively less additional absolute benefit. Multiple interventions should thus generally be reserved for patients at high risk for PONV or in whom PONV is especially dangerous.

While droperidol decreased PONV as much as the other antiemetics in the entire population, no benefit was demonstrated in men. This has not been described in previous studies, presumably because many were restricted to women and studies that included both sexes were too small to detect this interaction. Estrogen or other hormonal difference seems unlikely to be the cause since the effectiveness of droperidol was independent from menstrual cycle day and menopause (data not shown). Possibly, dopamine is a more important trigger in women than men. It is also possible that lack of droperidol efficacy in men is simply a spurious finding resulting from multiple testing.

It is well known that the incidence of PONV varies considerably among various sites of surgery. However, with the exception of hysterectomy and possibly cholecystectomy, relative risk was comparable for all surgery types when corrected for major risk factors including gender, nonsmoking status, history of PONV and postoperative opioids. As a consequence, risk models that include surgical site 1,32 provide no greater predictive power than a simplified model. 18,19 Since no interactions were detected between the interventions and the surgical site, repeating PONV studies for separate surgery sites is unnecessary. ${ }^{14,33}$

Management techniques such as total intravenous anesthesia cannot be used once PONV is established. Dexamethasone, similarly, prevents PONV only when given near the beginning of surgery, probably by reducing surgery-induced inflammation. ${ }^{34}$ Moreover, "rescue" treatments are ineffective when the same drug has already been used prophylactically. 35 Postoperative treatment options are thus limited compared to the broader range of prophylactic options, suggesting that prophylaxis may be preferable to treatment of established PONV. A reasonable treatment strategy would be to use dexamethasone and total intravenous anesthesia as first- and second-line prophylaxes for PONV, leaving serotonin antagonists as a rescue treatment.

\section{Acknowledgements}

We would like to thank Nancy L. Alsip, Ph.D., of the University of Louisville for editorial assistance.

\section{References}

1. Gan TJ. Postoperative nausea and vomiting--can it be eliminated? JAMA 2002;287:1233-6. [PubMed: 11886298]

2. Kovac AL. Prevention and treatment of postoperative nausea and vomiting. Drugs 2000;59:213-243. [PubMed: 10730546]

3. Watcha MF. Postoperative nausea and emesis. Anesthesiol Clin North America 2002;20:471-84.

4. Koivuranta M, Laara E, Snare L, Alahuhta S. A survey of postoperative nausea and vomiting. Anaesthesia 1997;52:443-449. [PubMed: 9165963]

5. Macario A, Weinger M, Carney S, Kim A. Which clinical anesthesia outcomes are important to avoid? The perspective of patients Anesth Analg 1999;89:652-658.

6. Darkow T, Gora-Harper ML, Goulson DT, Record KE. Impact of antiemetic selection on postoperative nausea and vomiting and patient satisfaction. Pharmacotherapy 2001;21:540-548. [PubMed: 11349743]

7. Schumann R, Polaner DM. Massive subcutaneous emphysema and sudden airway compromise after postoperative vomiting. Anesth Analg 1999;89:796-797. [PubMed: 10475327] 
8. Bremner WG, Kumar CM. Delayed surgical emphysema, pneumomediastinum and bilateral pneumothoraces after postoperative vomiting. Br J Anaesth 1993;71:296-297. [PubMed: 8123411]

9. Gold BS, Kitz DS, Kecky JH, Neuhaus JM. Unanticipated admission to the hospital following ambulatory surgery. JAMA 1989;262:3008-3010. [PubMed: 2810644]

10. Hill RP, Lubarsky DA, Phillips-Bute B, et al. Cost-effectiveness of prophylactic antiemetic therapy with ondansetron, droperidol, or placebo. Anesthesiology 2000;92:958-67. [PubMed: 10754614]

11. Watcha MF. The cost-effective management of postoperative nausea and vomiting. Anesthesiology 2000;92:931-933. [PubMed: 10754609]

12. Apfel CC, Kranke P, Katz MH, et al. Volatile anaesthetics may be the main cause for early but not delayed postoperative nausea and vomiting: a randomized controlled trial of factorial design. $\mathrm{Br} \mathrm{J}$ Anaesth 2002;88:659-668. [PubMed: 12067003]

13. Divatia JV, Vaidya JS, Badwe RA, Hawaldar RW. Omission of nitrous oxide during anesthesia reduces the incidence of postoperative nausea and vomiting. A meta-analysis Anesthesiology 1996;85:1055-1062.

14. Tramer MR. A rational approach to the control of postoperative nausea and vomiting: evidence from systematic reviews. Part I. Efficacy and harm of antiemetic interventions, and methodological issues. Acta Anaesthesiol Scand 2001;45:4-13. [PubMed: 11152031]

15. Scuderi PE, James RL, Harris L, Mims GR III. Multimodal antiemetic management prevents early postoperative vomiting after outpatient laparoscopy. Anesth Analg 2000;91:1408-1414. [PubMed: 11093990]

16. Gan T, Meyer T, Apfel C, et al. Consensus guidelines for the management of postoperative nausea and vomiting. Anesth Analg 2003;97:62-71. [PubMed: 12818945]

17. Apfel CC, Laara E, Koivuranta M, Greim CA, Roewer N. A simplified risk score for predicting postoperative nausea and vomiting: Conclusions from cross-validations between two centers. Anesthesiology 1999;91:693-700. [PubMed: 10485781]

18. Pierre S, Benais H, Pouymayou J. Apfel's simplified score may favourably predict the risk of postoperative nausea and vomiting. Can J Anesthesiol 2002;49:237-42.

19. Apfel CC, Kranke P, Eberhart LHJ, Roos IA, Roewer N. A comparison of predicting models for postoperative nausea and vomiting. British Br J Anaesth 2002;88:234-240.

20. Apfel CC, Korttila K, Abdalla M, Biedler A, Pocock S, Roewer N. An International Multicenter Protocol to Assess the Single and Combined Benefits of Antiemetic Strategies in a Controlled Clinical Trial of a $2 \times 2 \times 2 \times 2 \times 2 \times 2$ factorial design (IMPACT). Control Clin Trials 2003;24:736-751. [PubMed: 14662280]

21. Sneyd JR, Carr A, Byrom WD, Bilski AJ. A meta-analysis of nausea and vomiting following maintenance of anaesthesia with propofol or inhalational agents. Eur J Anaesthesiol 1998;15:433445. [PubMed: 9699101]

22. Greif R, Lacyni S, Rapf B, Hickle RS, Sessler DI. Supplemental oxygen reduces the incidence of postoperative nausea and vomiting. Anesthesiology 1999;91:1246-1252. [PubMed: 10551573]

23. Goll V, Akca O, Greif R, et al. Ondansetron is no more effective than supplemental intraoperative oxygen for prevention of postoperative nausea and vomiting. Anesth Analg esia 2001;92:112-117.

24. Purhonen S, Turunen M, Ruohoaho U-M, Niskanen M, Hynynen M. Supplemental oxygen does not reduce the incidence of postoperative nausea and vomiting after ambulatory gynecologic laparoscopy. Anesth Analg 2003;96:91-96. [PubMed: 12505931]

25. Joris JL, Poth NJ, Djamadar AM, et al. Supplemental oxygen does not reduce postoperative nausea and vomiting after thyroidectomy. Br J Anaesth 2003;91:857-61. [PubMed: 14633758]

26. Liu K, Hsu CC, Chia YY. The effect of dose of dexamethasone for antiemesis after major gynecological surgery. Anesth Analg 1999;89:1316-1318. [PubMed: 10553859]

27. Tang J, Wang B, White PF, Watcha MF, Qi J, Wender RH. The effect of timing of ondansetron administration on its efficacy, cost-effectiveness, and cost-benefit as a prophylactic antiemetic in the ambulatory setting. Anesth Analg 1998;86:274-282. [PubMed: 9459232]

28. Melnick B, Sawyer R, Karambelkar D, Phitayakorn P, Uy NT, Patel R. Delayed side effects of droperidol after ambulatory general anesthesia. Anesth Analg 1989;69:748-51. [PubMed: 2589655]

29. Lim BS, Pavy TJ, Lumsden G. The antiemetic and dysphoric effects of droperidol in the day surgery patient. Anaesthes Intensive Care 1999;27:371-374. 
30. Gan TJ, White PF, Scuderi PE, Watcha MF, Kovac A. FDA "black box" warning regarding use of droperidol for postoperative nausea and vomiting: is it justified? Anesthesiology 2002;97:287. [PubMed: 12131145]

31. Henzi I, Walder B, Tramer MR. Dexamethasone for the prevention of postoperative nausea and vomiting: a quantitative systematic review. Anesth Analg 2000;90:186-194. [PubMed: 10625002]

32. Sinclair DR, Chung F, Mezei G. Can postoperative nausea and vomiting be predicted? Anesthesiology 1999;91:109-118. [PubMed: 10422935]

33. Apfel CC, Roewer N, Korttila K. How to study postoperative nausea and vomiting. Acta Anaesthesiol Scand 2002;46:921-8. [PubMed: 12190791]

34. Wang JJ, Ho ST, Tzeng JI, Tang CS. The effect of timing of dexamethasone administration on its efficacy as a prophylactic antiemetic for postoperative nausea and vomiting. Anesth Analg 2000;91:136-9. [PubMed: 10866900]

35. Kovac AL, O'Connor TA, Pearman MH, et al. Efficacy of repeat intravenous dosing of ondansetron in controlling postoperative nausea and vomiting: a randomized, double-blind, placebo- controlled multicenter trial. Journal of Clinical Anesthesia 1999;11:453-459. [PubMed: 10526822]

\section{Appendix}

\section{Steering Committee}

Christian C. Apfel, MD, Outcomes Research ${ }^{\mathrm{TM}}$ Group and Department of Anesthesiology,

University of Wuerzburg; Kari Korttila, MD, PhD, FRCA, Department of Anesthesiology and Intensive Care, University of Helsinki; and Andreas Biedler, MD, Department of Anesthesiology, University Hospital of the Saarland.

\section{Data Management and Monitoring}

Christian C. Apfel, MD, E. Kaufmann, MD, M. Kredel, MD, A. Schmelzer, MD, J. Wermelt, MD, Department of Anesthesiology, University of Wuerzburg; and G. Link, DatabaseEngineering, Rimpar, Germany.

\section{Manuscript Preparation and Data Analyses}

Christian C. Apfel, MD, Outcomes Research ${ }^{\mathrm{TM}}$ Group and Department of Anesthesiology, University of Wuerzburg; Daniel I. Sessler, M.D., Outcomes RESEARCH ${ }^{\mathrm{TM}}$ Institute and Departments of Anesthesiology and Pharmacology, University of Louisville, Stuart J Pocock, PhD, and Mona Abdalla, PhD, Statistics Unit, London School of Hygiene and Tropical Medicine.

\section{Site Investigators}

\begin{tabular}{|c|c|c|c|}
\hline $\mathbf{N}$ & Investigators & Institution & City, Country \\
\hline 479 & A. Turan, MD & $\begin{array}{l}\text { Department of Anesthesiology, Trakya } \\
\text { Üniversitesi }\end{array}$ & Edirne,Turkey \\
\hline 424 & $\begin{array}{l}\text { E. Kaufmann, MD, P. Kranke, MD, M. } \\
\text { Kredel, MD, N. Roewer, MD, A. } \\
\text { Schmelzer, MD, J Wermelt }\end{array}$ & $\begin{array}{l}\text { Klinik und Poliklinik für, Anästhesiologie, Julius- } \\
\text { Maximilians Universität }\end{array}$ & Wuerzburg, Germany \\
\hline 384 & $\begin{array}{l}\text { R.M. Jokela, MD, A. Soikkeli, MD, K. } \\
\text { Korttila, MD }\end{array}$ & $\begin{array}{l}\text { Department of Anesthesiology and Intensive Care, } \\
\text { Helsinki University, Central Hospital }\end{array}$ & Helsinki, Finland \\
\hline 288 & $\begin{array}{l}\text { C. Isselhorst, MD, B. Fritz, MD, H. } \\
\text { Kerger, MD }\end{array}$ & $\begin{array}{l}\text { Department of Anesthesiology, University } \\
\text { Hospital Mannheim }\end{array}$ & Mannheim, Germany \\
\hline 268 & $\begin{array}{l}\text { O. Danzeisen, MD, C. Heringhaus, MD, I. } \\
\text { Schramm, S. Spieth }\end{array}$ & $\begin{array}{l}\text { Department of Anesthesiology, Universität } \\
\text { Freiburg }\end{array}$ & Freiburg, Germany \\
\hline 196 & L. Eberhart, MD, K. Werthwein MD & Department of Anesthesiology Universität Ulm & Ulm, Germany \\
\hline 192 & $\begin{array}{l}\text { W. Leidinger, MD, J.N. Meierhofer, MD, } \\
\text { U. Ruppert, MD, C. Zernak, MD }\end{array}$ & $\begin{array}{l}\text { Abteilung für Anästhesiologie, operative } \\
\text { Intensivmedizin und Blutprodukte, } \\
\text { Kreiskrankenhaus Garmisch-Patenkirchen }\end{array}$ & $\begin{array}{l}\text { Garmisch- } \\
\text { Patenkirchen, Germany }\end{array}$ \\
\hline 192 & A. Bacher, MD & $\begin{array}{l}\text { Klinik für Anästhesie und Allgemeine, } \\
\text { Intensivmedizin, Universität Wien }\end{array}$ & Wien, Austria \\
\hline
\end{tabular}




\begin{tabular}{|c|c|c|c|}
\hline $\mathbf{N}$ & Investigators & Institution & City, Country \\
\hline 191 & H. Bartsch, MD, H. Forst, MD & $\begin{array}{l}\text { Department of Anesthesiology and Surgical } \\
\text { Intensive Care, Zentralklinikum Augsburg }\end{array}$ & Augsburg, Germany \\
\hline 191 & $\begin{array}{l}\text { B. Book, MD, W. Hoeltermann, MD, C. } \\
\text { Prause, MD }\end{array}$ & Department of AnesthesiologyKlinikum Lingen & Lingen, Germany \\
\hline 191 & E. Palencikova, MD, S. Trenkler, MD & Department of Anesthesiology & Presov, Slovakia \\
\hline 190 & $\begin{array}{l}\text { H. Bause, MD, H. Bordon, MD, K. } \\
\text { Stoecklein, MD }\end{array}$ & $\begin{array}{l}\text { Department of Anesthesiology, Allgemeines, } \\
\text { Krankenhaus Altona }\end{array}$ & Hamburg-Altona, Germany \\
\hline 189 & $\begin{array}{l}\text { F. Bach, MD, D. Buschmann, MD, F. } \\
\text { Mertzlufft, MD, I. Vedder, MD }\end{array}$ & $\begin{array}{l}\text { Department of Anesthesiology and surgical } \\
\text { intensive care, v. Bodelschwingsche Anstalten } \\
\text { Bethel }\end{array}$ & Bielefeld, Germany \\
\hline 189 & C. Frenkel, MD, A. Paura, MD & $\begin{array}{l}\text { Department of Anesthesiology, Klinikum } \\
\text { Lüneburg }\end{array}$ & Lüneburg, Germany \\
\hline 185 & $\begin{array}{l}\text { K. Danner, MD, C. Madler, MD, B. } \\
\text { Steinbrecher, MD }\end{array}$ & $\begin{array}{l}\text { Institut für Anästhesiologie und Notfallmedizin, } \\
\text { Westpfalz-Klinikum }\end{array}$ & Kaiserslautern, Germany \\
\hline 183 & $\begin{array}{l}\text { A. Kimmich, MD, E. Schneider, MD, M. } \\
\text { Trick, MD }\end{array}$ & $\begin{array}{l}\text { Department of Anesthesiology, Universitätsklinik } \\
\text { Tübingen }\end{array}$ & Tübingen, Germany \\
\hline 181 & $\begin{array}{l}\text { A. Biedler, MD, D. Detzel, MD, W. } \\
\text { Wilhelm, MD }\end{array}$ & $\begin{array}{l}\text { Klinik fuer Anaesthesiologie und Intensivmedizin, } \\
\text { Universitaetskliniken des Saarlandes }\end{array}$ & Homburg, Germany \\
\hline 181 & M. Koivuranta, MD & $\begin{array}{l}\text { Department of Anesthesiology, Central Lapland } \\
\text { Hospital }\end{array}$ & Rovaniemi, Finland \\
\hline 180 & $\begin{array}{l}\text { M. Hinojosa, MD, M. Lucas, MD, S. } \\
\text { Muñoz, PhD, R. Rincon, MD, P. Vila, MD }\end{array}$ & $\begin{array}{l}\text { Department of Anesthesiology, Hospital } \\
\text { Universitario Germans Trias I Pujol, Badalona }\end{array}$ & Barcelona, Spain \\
\hline 154 & M. Hergert, MD, F. Liebenow, MD & $\begin{array}{l}\text { Department of Anesthesiology and Intensive care, } \\
\text { Klinikum Schwerin }\end{array}$ & Schwerin, Germany \\
\hline 118 & H.-B. Hopf, MD, S. Pohl, MD & Department of Anesthesiology Kreisklinik Langen & Langen, Germany \\
\hline 113 & G. Frings, MD & Anesthesiology Unit, Wedau-Kliniken & Duisburg, Germany \\
\hline 91 & G. Fritz, MD, C. Hoehne, MD & $\begin{array}{l}\text { Department of Anesthesiology, Charité, Campus } \\
\text { Virchow-Klinikum }\end{array}$ & Berlin, Germany \\
\hline 89 & H. Feierfeil, MD, J. Motsch, MD & $\begin{array}{l}\text { Department of Anesthesiology, Universität } \\
\text { Heidelberg }\end{array}$ & Heidelberg, Germany \\
\hline 77 & A. Goebel, MD & $\begin{array}{l}\text { Department of Anesthesiology, Eichhof } \\
\text { Krankenhaus }\end{array}$ & Lauterbach, Germany \\
\hline 31 & $\begin{array}{l}\text { S. Alahuhta, MD, T. Kangas-Saarela, MD, } \\
\text { P. Karjaleinen, MD }\end{array}$ & $\begin{array}{l}\text { Department of Anesthesiology, Oulu University } \\
\text { Hospital }\end{array}$ & Oulu, Finland \\
\hline 31 & R. Sneyd, MD & Department of Anaesthetics, Derriford Hospital & Plymouth, UK \\
\hline 13 & Koschel, MD, M. Lange, MD & $\begin{array}{l}\text { Department of Anesthesiology, Waldkrankenhaus } \\
\text { Rudolf Elle }\end{array}$ & Eisenberg, Germany \\
\hline
\end{tabular}

$\mathrm{N}$ indicates the number of patients enrolled at each site. 


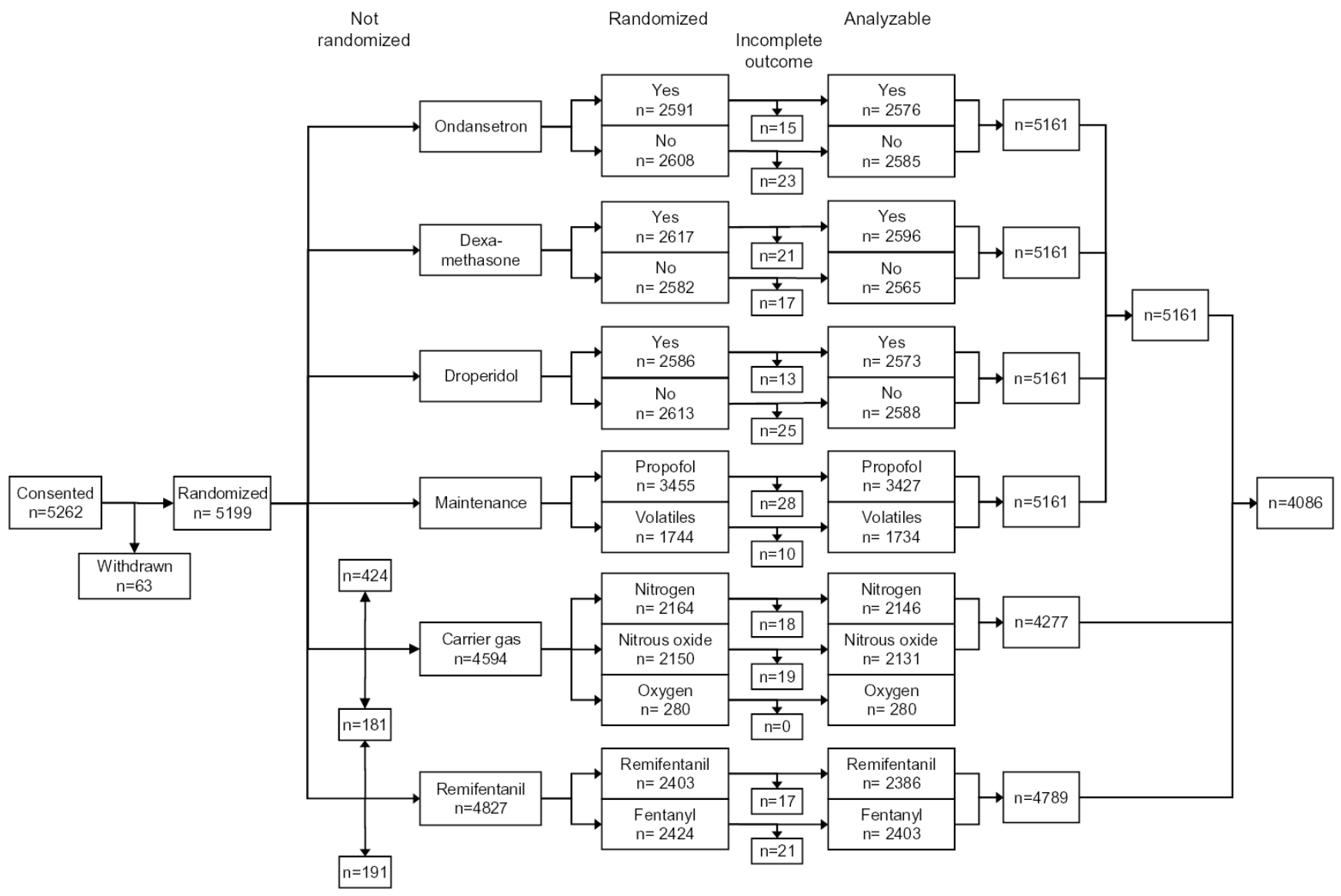

Fig. 1.

Trial profile. Due to the factorial design, patients were simultaneously randomized to several interventions. One center each was unable to randomize for nitrogen $(n=424)$, remifentanil (191), or both (181). A total of 4123 patients were thus factorially randomized to all six primary factors with 4086 providing analyzable data. 


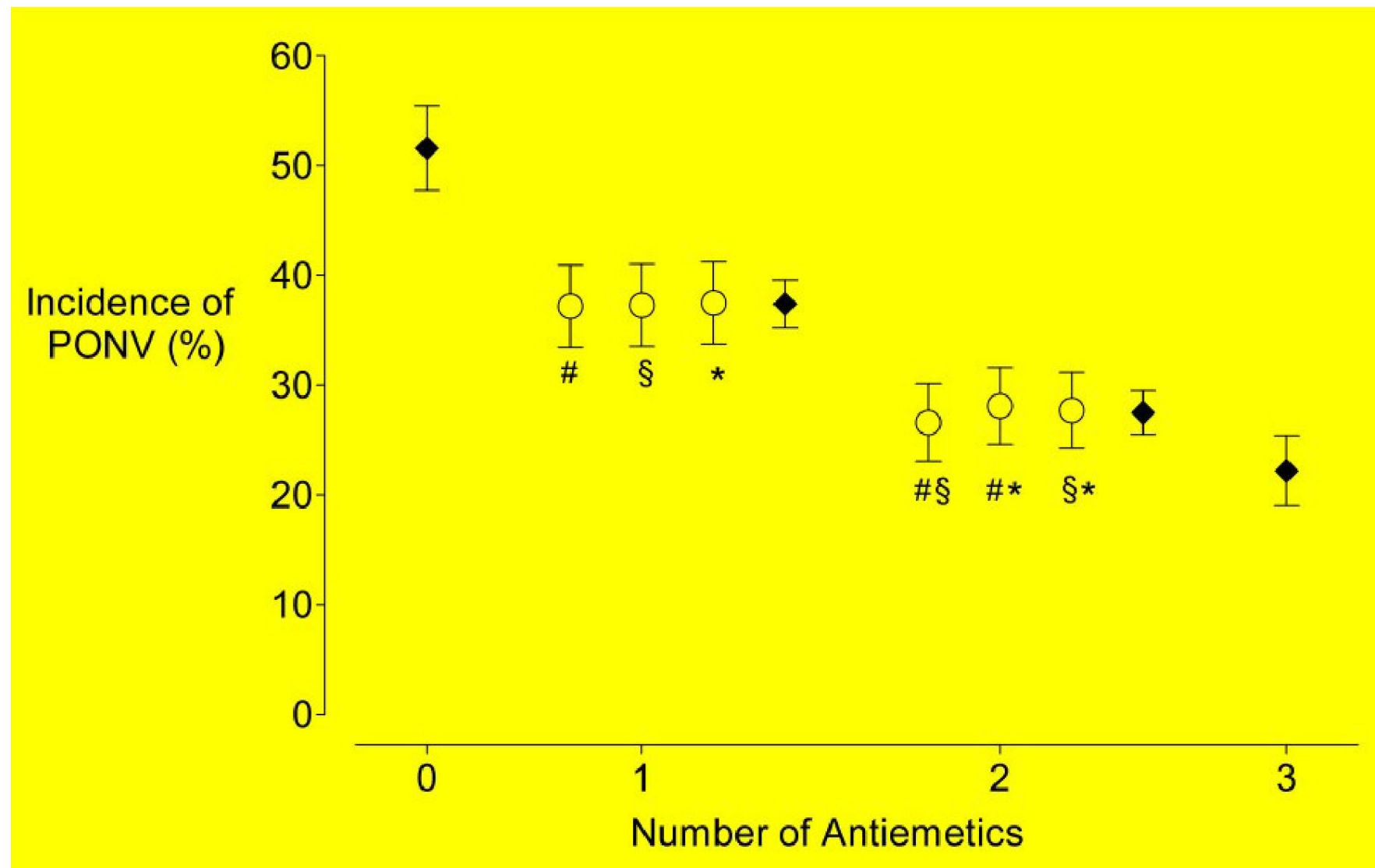

Fig. 2.

Percentage of patients with PONV ( $\pm 95 \%$ confidence intervals) according to the various combinations of antiemetic drugs based on 5161 patients. Filled circles show the means of all patients given $0,1,2$, or 3 antiemetics. Plus symbols (\#) represent patients who received ondansetron; section symbols $(\S)$, those who received dexamethasone; and daggers $(\dagger)$, whose who received droperidol. 
Fig. 3.

Percentage of 4086 patients randomized to all interventions with PONV $( \pm 95 \%$ confidence intervals) according to the combinations of anesthetic strategies and the number of anti-emetic treatments given. Because remifentanil did not contribute significantly to the PONV risk, it is not displayed in this figure. Although the figure suggests there is an interaction between nitrogen and propofol in patients with no antiemetics, statistical analyses did not confirm this impression. 
Patients with PONV.

Table 1

\begin{tabular}{|c|c|c|c|c|}
\hline \multirow[b]{2}{*}{ Intervention } & \multicolumn{2}{|c|}{ Received Intervention } & \multirow[b]{2}{*}{$\begin{array}{c}\text { Relative risk (\% }[95 \% \\
\text { CI] })\end{array}$} & \multirow[b]{2}{*}{ P(chi-square) } \\
\hline & Yes PONV ${ }^{*} / \mathbf{N}^{\dagger}(\%)$ & No PONV/N (\%) & & \\
\hline Ondansetron & $735 / 2576(28.5)$ & $996 / 2585(38.5)$ & $-26.0(-19.9$ to -31.5$)$ & $<0.001$ \\
\hline Dexamethasone & $739 / 2596(28.5)$ & $992 / 2565(38.7)$ & $-26.4(-20.4$ to -31.9$)$ & $<0.001$ \\
\hline Droperidol & $742 / 2573(28.8)$ & $989 / 2588(38.2)$ & $-24.5(-18.4$ to -30.2$)$ & $<0.001$ \\
\hline $\begin{array}{l}\text { Propofol vs. inhalational } \\
\text { anesthetics }\end{array}$ & $1066 / 3427(31.1)$ & 665/1734 (38.4) & $-18.9(-12.3$ to -25.0$)$ & $<0.001$ \\
\hline $\begin{array}{l}\text { Air with 30\% oxygen vs. } \\
\text { nitrous oxide }\end{array}$ & $668 / 2146(31.1)$ & 755/2131 (35.4) & $-12.1(-4.3$ to -19.3$)$ & 0.003 \\
\hline Remifentanil vs. fentanyl & $827 / 2386(34.7)$ & $792 / 2403(33.0)$ & $5.2(13.8$ to -2.9$)$ & 0.21 \\
\hline
\end{tabular}

${ }^{*}$ PONV $=$ Number of patients suffering postoperative nausea, vomiting, or both.

${ }^{\dagger} \mathrm{N}=$ total number of patients randomized with complete outcome for the intervention under investigation. The data are based on all 5161 randomized patients that completed the study with the exceptions of carrier gas $(\mathrm{N}=4277)$ and remifentanil $(\mathrm{N}=4789)$ to assure group comparability (see also figure $1)$. 
Table 2

Multiple logistic regression analysis of the $5161^{*}$ (randomized to ondansetron, dexamethasone, droperidol, and propofol) and 4086 patients (randomized to all six interventions)

\begin{tabular}{|c|c|c|c|c|c|c|}
\hline & \multicolumn{3}{|c|}{5161 Patients } & \multicolumn{3}{|c|}{4086 Patients } \\
\hline & $\begin{array}{l}\text { Odds } \\
\text { ratio }\end{array}$ & $95 \% \mathrm{CI}$ & $\mathbf{P}$ & $\begin{array}{l}\text { Odds } \\
\text { ratio }\end{array}$ & $95 \% \mathrm{CI}$ & $\mathbf{P}$ \\
\hline Ondansetron & 0.56 & $(0.50,0.64)$ & $<0.001$ & 0.56 & $(0.48,0.65)$ & $<0.001$ \\
\hline Dexamethasone & 0.57 & $(0.50,0.65)$ & $<0.001$ & 0.57 & $(0.49,0.66)$ & $<0.001$ \\
\hline Droperidol & 0.58 & $(0.51,0.67)$ & $<0.001$ & 0.56 & $(0.48,0.66)$ & $<0.001$ \\
\hline Propofol & 0.69 & $(0.60,0.79)$ & $<0.001$ & 0.71 & $(0.61,0.83)$ & $<0.001$ \\
\hline \multicolumn{7}{|l|}{ Carrier gas } \\
\hline Nitrogen $(30 \% 02)$ & 0.81 & $(0.70,0.93)$ & 0.003 & 0.83 & $(0.72,0.97)$ & 0.02 \\
\hline Nitrogen $(80 \% 02)$ & 0.99 & $(0.70,1.40)$ & 0.96 & & & \\
\hline Remifentanil & 0.96 & $(0.84,1.10)$ & 0.56 & 0.94 & $(0.81,1.09)$ & 0.39 \\
\hline Female & 3.13 & $(2.33,4.20)$ & $<0.001$ & 2.87 & $(2.08,3.95)$ & $<0.001$ \\
\hline $\begin{array}{l}\text { Male by droperidol } \\
\text { interaction }\end{array}$ & 1.85 & $(1.26,2.72)$ & 0.002 & 1.97 & $(1.29,3.00)$ & 0.002 \\
\hline Non-smoking & 1.57 & $(1.32,1.87)$ & $<0.001$ & 1.57 & $(1.29,1.91)$ & $<0.001$ \\
\hline $\begin{array}{l}\text { History of PONV or } \\
\text { motion sickness }\end{array}$ & 1.70 & $(1.49,1.95)$ & $<0.001$ & 1.80 & $(1.54,2.09)$ & $<0.001$ \\
\hline \multicolumn{7}{|l|}{ Operations } \\
\hline Hernia repair & 1.04 & $(0.65,1.67)$ & 0.87 & 1.08 & $(0.66,1.78)$ & 0.75 \\
\hline Cholecystectomy & 1.49 & $(1.08,2.06)$ & 0.015 & 1.44 & $(1.01,2.05)$ & 0.04 \\
\hline Hysterectomy & 1.78 & $(1.35,2.35)$ & $<0.001$ & 1.94 & $(1.43,2.63)$ & $<0.001$ \\
\hline Thyroid & 1.22 & $(0.86,1.72)$ & 0.27 & 1.23 & $(0.85,1.78)$ & 0.27 \\
\hline Breast & 0.74 & $(0.48,1.17)$ & 0.20 & 0.76 & $(0.46,1,24)$ & 0.27 \\
\hline Orthopedic surgery & 0.91 & $(0.67,1.24)$ & 0.55 & 0.91 & $(0.65,1.29)$ & 0.60 \\
\hline Head and neck & 1.08 & $(0.71,1.65)$ & 0.72 & 0.88 & $(0.55,1.42)$ & 0.61 \\
\hline Other gynecologic & 0.91 & $(0.69,1.19)$ & 0.48 & 0.98 & $(0.73,1.32)$ & 0.91 \\
\hline $\begin{array}{l}\text { Duration of anesthesia } \\
\text { (per h) }\end{array}$ & 1.20 & $(1.12,1.28)$ & $<0.001$ & 1.15 & $(1.06,1.24)$ & 0.001 \\
\hline Postoperative opioids & 2.14 & $(1.75,2.61)$ & $<0.001$ & 2.01 & $(1.59,2.53)$ & $<0.001$ \\
\hline
\end{tabular}

* Corrected for the center as a potentially confounding factor.

$* *$

Odds ratio describe the effects of the interventions or presence of covariates compared to those where the intervention or covariate is absent. 
Table 3

Estimated PONV incidence as a function of baseline risk, assuming each intervention reduces relative risk $26 \%$. Values are presented as percentages.

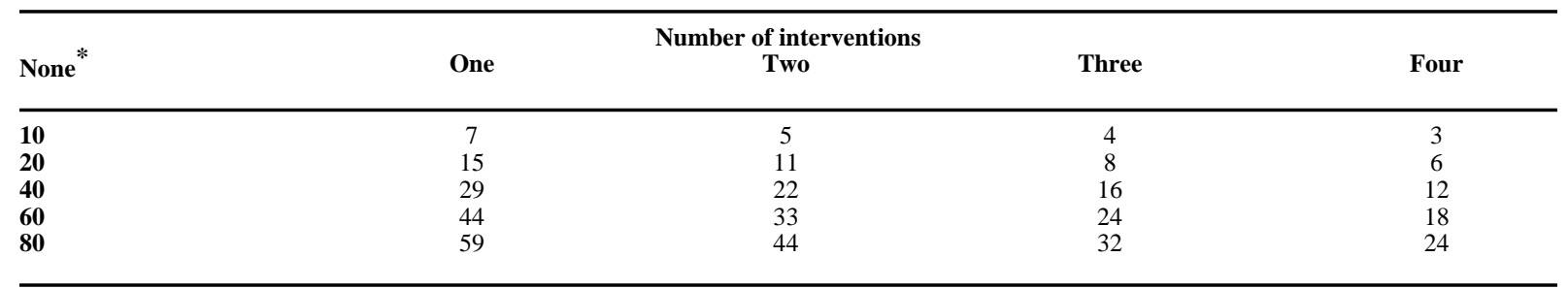

The exemplified baseline risk levels of $10 \%, 20 \%, 40 \%, 60 \%$ and $80 \%$ reflect $0,1,2,3$, and 4 risk factors considered in a simplified risk score. ${ }^{17}$ 